\title{
Vemurafenib Sensitizes Melanoma Cells to Temozolomide by Downregulating MGMT Expression.
}

\section{Bingjie Ren}

Soochow University Affiliated No 1 People's Hospital: First Affiliated Hospital of Soochow University Qiang Li

Jiangxi Tumor Hospital: Jiangxi Cancer Hospital

\section{Jing Zhao}

Soochow University Affiliated No 1 People's Hospital: First Affiliated Hospital of Soochow University

\section{Xia Guo}

Soochow University Affiliated No 1 People's Hospital: First Affiliated Hospital of Soochow University

\section{Yingxi Hu}

Soochow University Affiliated No 1 People's Hospital: First Affiliated Hospital of Soochow University

\section{Mengyao Wu}

Soochow University Affiliated No 1 People's Hospital: First Affiliated Hospital of Soochow University

\section{Dapeng Li}

Soochow University Affiliated No 1 People's Hospital: First Affiliated Hospital of Soochow University

\section{Daoming Li}

Soochow University Affiliated No 1 People's Hospital: First Affiliated Hospital of Soochow University Min Tao

Soochow University Affiliated No 1 People's Hospital: First Affiliated Hospital of Soochow University Rongrui Liang ( $\square$ lengbeng@suda.edu.cn )

First Affiliated Hospital of Soochow University https://orcid.org/0000-0001-9879-2808

\section{Research}

Keywords: Vemurafenib, Temozolomide, Chemosensitivity, MGMT, MAPK/ERK pathway, Melanoma

Posted Date: October 1st, 2020

DOI: https://doi.org/10.21203/rs.3.rs-83301/v1

License: (c) (i) This work is licensed under a Creative Commons Attribution 4.0 International License. Read Full License 


\section{Abstract}

\section{Background}

The alkylating agent temozolomide (TMZ) is widely used to treat melanoma in clinical practice. However, cells expressing the DNA repair enzyme $0^{6}$-methylguanine-DNA methyltransferase (MGMT) are highly resistant to this drug. Vemurafenib (VMF), a targeted BRAF kinase inhibitor, is applied to treat BRAF-V600 mutant metastatic melanoma. Studies have suggested that blocking this pathway prevents MGMT from affecting TMZ sensitization. However, reports of the use of the combination of VMF and TMZ in the treatment of melanoma are lacking.

Methods

Cell viability was detected by MTT assay, cell apoptosis was assayed by flow cytometry, and the mRNA level of the MGMT gene was measured by RT-qPCR. Western blotting, immunofluorescence staining were utilized to determine the expression of the protein. The pcDNA3.1-MGMT vector was transiently transfected to generate MGMT-overexpressing cells for experiments. A nude mouse malignant melanoma xenograft model was established for in vivo drug experiments.

Results

VMF increased TMZ-induced cytotoxicity by increasing DNA damage. VMF inhibited the MAPK/ERK signaling pathway and the mRNA and protein expression of the MGMT gene. VMF did not inhibit MGMT protein expression in A375-MGMT OE cells, and the vMF-induced sensitization effect was attenuated. Moreover, TMZ exposure activated ERK activity in malignant melanoma. The expression of MGMT and $p$ ERK1/2 was positively correlated in melanoma tissues.

\section{Conclusion}

VMF sensitized melanoma to TMZ by inhibiting the MAPK/ERK-MGMT pathway, and the combination of VMF and TMZ is expected to improve the clinical treatment effect on malignant melanoma.

\section{Background}

Malignant melanoma (MM) is the most aggressive cancer of the skin. The incidence of MM has been increasing for years, with 100,350 annual new cases and 6,850 deaths related to MM reported in 2020[1] . Because of the application of targeted therapies and immune-checkpoint inhibitors, the mortality of MM has recently declined; however, the global prognosis of MM, especially in AJCC stage IV disease, remains poor. Despite the development of treatment, the 5 -year overall survival is still under $40 \%$ for this fatal disease[2] . The Food and Drug Administration (FDA) approved vemurafenib (vMF) as the first targeted drug for the treatment of metastatic melanoma in 2011. According to the BRIM-3 trial, vMF treatment results in improvements in progression-free survival (PFS) and overall survival (OS) in advanced MM patients with the BRAF ${ }^{\mathrm{V} 600 \mathrm{E}}$ mutation[3] . Extended follow-up indicated that vMF continues to be 
associated with improved mOS as well as $\operatorname{mPFS}[4,5]$. These data provide persuasive evidence for the application of VMF in BRAF ${ }^{\mathrm{V} 600 \mathrm{E}} \mathrm{MM}$ patients.

In patients with advanced MM who do not harbor somatic mutations, chemotherapy and immunotherapy could play crucial roles in the treatment regime. Chemotherapeutic drugs such as paclitaxel, dacarbazine, platins, and temozolomide (TMZ) are commonly applied in advanced MM. TMZ is an oral alkylating agent derived from dacarbazine in vivo, and this drug was originally approved by the FDA for the treatment of glioblastoma[6, 7]. As the clinical application of TMZ progresses, it has been approved for the treatment of metastatic melanoma. A phase III study in advanced MM demonstrated significantly longer PFS and improved quality of life in the TMZ arm compared to the dacarbazine arm[8] . Compared to most chemotherapeutic drugs, TMZ can cross the blood-brain barrier more efficiently, which provides a basis for the prevention or treatment of central nervous system metastases by TMZ. The primary mechanism of action of TMZ is DNA alkylation and the inhibition of other targets. In recent decades, however, there has been little progression in the development of chemotherapeutic drugs for melanoma, and with current agents, the overall response rates (ORR) are usually disappointing. Chemoresistance is still the most common cause of therapy failure. Several repair mechanisms contribute to resistance to TMZ, and the primary mechanism involves $0^{6}$-methylguanine-DNA methyltransferase (MGMT). MGMT is a DNA repair protein that can transfer a methyl group from guanine to a cysteine residue; it can also efficiently remove alkylating lesions at the $0^{6}$ position of guanine and repair the cytotoxic lesions induced by alkylating agents such as dacarbazine (DTIC) and TMZ, resulting in drug resistance. It has been repeatedly reported that TMZ shows low cytotoxicity in tumors with high MGMT activity and that high levels of MGMT in brain and other tumors are correlated with resistance to TMZ. The downregulation of MGMT expression could enhance the cytotoxicity of alkylating agents in tumor cells. There are several mechanisms for the downregulation of MGMT gene expression that can be considered in the development of new strategies for decreasing chemoresistance and enhancing the antitumor ability of alkylating agents.

Unfortunately, the systemic clinical application of MGMT inhibitors has been restricted mainly because of an increase in the hematologic toxicity to DNA alkylators and failure to restore TMZ sensitivity to TMZresistant glioblastoma multiforme. Numerous studies have revealed that the transcription factor p53 is also associated with the inhibition of MGMT and consequently alters the sensitivity of tumor cells to alkylating agents[9-11] . In addition, there is evidence that the adenovirus E1A protein could inhibit MGMT expression by binding to and inactivating $\mathrm{p300[12]} \mathrm{.} \mathrm{A} \mathrm{study} \mathrm{showed} \mathrm{that} \mathrm{the} \mathrm{MEK} \mathrm{inhibitors} \mathrm{SL327} \mathrm{and}$ U0126 suppressed the expression of MGMT in glioblastoma (GBM) [13] . Hence, MGMT expression could be regulated by multiple molecular mechanisms, and searching for regulators of MGMT may shed light on the sensitization of cancer cells to alkylating agents. To develop treatment options, new treatment advances, including new candidate drugs, novel regimens or combinations thereof, have been tested in clinical trials. Although this field has not seen new advances in decades, the development of new drugs with distinct mechanisms emphasizes the use of the combined strategy in MM patients. As mentioned

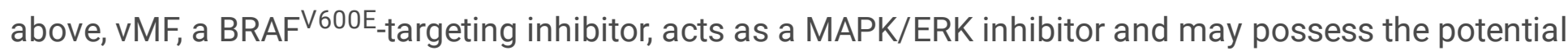


ability to sensitize MM cells to DNA alkylators. Since vMF has been applied in MM treatment for years, its safety has been confirmed, conferring this target drug with a unique advantage over previous MGMT inhibitors for clinical application. In this study, we investigated the effect of vMF on sensitizing cells to TMZ in MM and identified the role of the MAPK/ERK pathway in VMF-induced sensitization.

\section{Materials And Methods}

\section{Cell lines and culture}

A375 and SK-MEL28 cells were acquired from the Guangzhou National Center Cell Bank (NECB). The cells were cultured in DMEM (HyClone) containing 10\% FBS (HyClone). Cells were incubated at $37^{\circ} \mathrm{C}$ under $5 \%$ $\mathrm{CO}_{2}$.

\section{Tissue assay and immunohistochemistry}

The human melanoma tissue arrays utilized in this investigation were obtained from Shaanxi Alenabio Co., LTD. and were composed of 32 radical prostatectomy-derived melanoma skin specimens and 16 metastatic lymph nodes. All human tissues were collected under IRB- and HIPPA-approved protocols. All samples tested negative for HIV and hepatitis B or their counterparts in animals and were approved for commercial product development. The age, sex, specimen derivation, and TNM stages are listed in Supplemental Table S1. The intracellular locations and expression of MGMT and p-ERK in the tissue assay were examined by immunohistochemistry. Antigen retrieval was carried out in a microwave oven for 15 minutes in TEG buffer ( $10 \mathrm{mM}$ Tris, $0.5 \mathrm{mM}$ ethylene glycol tetraacetic acid, $\mathrm{pH}$ 9). Incubation with anti-MGMT (1:200) and anti-pERK1/2 (1:100) antibodies for $1 \mathrm{~h}$ was followed by the evaluation of the primary antibody by applying the Advance ${ }^{\mathrm{TM}} \mathrm{HRP}$ system (DAKO). The chromogen 3,3'-diaminobenzidine was utilized, and all staining procedures were carried out with an Autostainer Plus Link Instrument (DAKO). After rinsing, the slides were counterstained with Meyer's hematoxylin for thirty seconds. All antibodies mentioned above were from obtained CST (Danvers, MA, USA).

\section{Animals}

Male BALB/c nude mice (four weeks old) were acquired from the Nanjing Experimental Animal Center and maintained in the Laboratory Animal Center of the First Affiliated Hospital of Soochow University, in accordance with the Soochow University Institutional Animal Care and Use Committee. A total of $1 \times 10^{6}$ A375 cells resuspended in $200 \mu$ of PBS were subcutaneously injected in the right inguinal area in male nude mice (five weeks old). Tumors were visible in all mice. The mice were separated into three groups $(\mathrm{n}=6)$ : group I, treatment with DMSO; group II, treatment with $20 \mathrm{mg} / \mathrm{kg} \cdot \mathrm{d}$ TMZ; group III, treatment with 20 $\mathrm{mg} / \mathrm{kg} \cdot \mathrm{d} \mathrm{TMZ}$ and $20 \mathrm{mg} / \mathrm{kg} \cdot \mathrm{d}$ vemurafenib. The treatments were performed seven days after the injection of A375 cells. Tumors were measured with a Vernier caliper every two days, and tumor volumes were calculated utilizing the formula: volume $=\left(\right.$ length $\times$ width $\left.{ }^{2}\right) / 2$ and expressed as the mean size \pm standard error. 


\section{MGMT-overexpressing plasmids and their transfection}

The pcDNA3.1-MGMT vector was produced by Sangon Biotech (Shanghai) Co., Ltd. The plasmid sequence was verified by DNA sequencing. Cells were seeded in six-well plates at a cell count of $1 \times 10^{5}$ $24 \mathrm{~h}$ before transfection. Lipofectamine 3000 (Thermo Fisher Scientific Inc.) was utilized to perform transfection with $5.0 \mu \mathrm{g}$ of the pcDNA3.1(+)-MGMT vector or $5.0 \mu \mathrm{g}$ of the pcDNA3.1(+) empty vector (as a negative control) following the manufacturer's instructions.

\section{Assessment of cell viability and apoptosis}

Cell viability was detected by the MTT assay as previously reported (11). After the treatment of cells with the indicated agent for $24 \mathrm{~h}, 48 \mathrm{~h}$ or $72 \mathrm{~h}$, the cells were rinsed two times with PBS and incubated with MTT $(0.5 \mathrm{mg} / \mathrm{ml}$; Sigma) for $4 \mathrm{~h}$. The reagent was absorbed by living cells and ultimately formed an insoluble blue formazan product. The formazan product was solubilized with DMSO and quantified using a microplate reader at an absorbance of $550 \mathrm{~nm}$. The inhibition rate and $I C_{50}$ were calculated utilizing SPSS software (version 26.0, SPSS Inc, Chicago, IL). The growth inhibition rate was calculated as follows: growth inhibition rate $=(1-\mathrm{A} 570$ value of the drug treated group $/ \mathrm{A} 570$ value of the control untreated group) $\times 100 \%$. The apoptosis rate was evaluated with an Annexin V-FITC/PI Apoptosis Detection Kit (Signalway Antibody; College Park, USA). A375 cells were seeded in six-well plates and treated with TMZ and VMF, either alone or in combination, for $12 \mathrm{~h}$. The cells were washed twice using PBS and resuspended in $400 \mu \mathrm{l}$ of $1 \times$ binding buffer. Annexin V-FITC A (5 $\mu$ l) was added to the cell suspension, which was subsequently gently mixed and incubated for fifteen minutes at $2-8^{\circ} \mathrm{C}$ protected from light. Then, $10 \mu$ of PI was added, followed by mixing for 5 minutes at $2-8^{\circ} \mathrm{C}$ protected from light. The flow cytometry analysis of apoptotic cells (Beckman, CA, USA).

\section{Western blotting}

Western blotting was performed as previously described (15). Whole-cell extracts were prepared from A375 cells incubated in six-well plates. After incubation, the cells were collected and rinsed with PBS and lysed in extraction buffer $(40 \mathrm{mmol} / \mathrm{I}$ Tris-HCl, $\mathrm{pH}$ 7.5, $150 \mathrm{mmol} / \mathrm{I} \mathrm{KCl}, 1 \mathrm{mmol} / \mathrm{I} \mathrm{EDTA}, 1 \%$ Triton X-100, $100 \mathrm{mmol} / \mathrm{I} \mathrm{NaVO}_{3}, 1 \mathrm{mmol} / \mathrm{I}$ PMSF) supplemented with a protease inhibitor cocktail. The obtained protein $(50 \mu \mathrm{g})$ was separated via SurePAGE ${ }^{\mathrm{TM}}$ Bis-Tris gradient concentration (4-20\%) SDS-PAGE (Genscript Biotech Corporation, Nanjing, China) and transferred to a PVDF filter. The filters were blocked using $5 \%$ nonfat milk for $2 \mathrm{~h}$ at room temperature and then incubated with a rabbit anti-MEK1 antibody (1:1000), rabbit anti-p-MEK1 antibody (1:1000), mouse anti-ERK1/2 antibody (1:1000), rabbit anti-pERK1/2 antibody (1:1000), rabbit anti-p-chk1 antibody (1:1000), rabbit anti-p-chk2 antibody (1:1000), rabbit anti-p-ATR antibody (1:1000), rabbit anti-p-ATM antibody (1:1000), rabbit anti- $-\mathrm{H} 2 \mathrm{AX}(1: 1000)$ antibody, rabbit anti-MGMT antibody (1:2000), or mouse anti- $\beta$-actin antibody (1:500) for $12 \mathrm{~h}$ at $4^{\circ} \mathrm{C}$. Horseradish peroxidase-linked anti-mouse $\lg G(1: 5000)$ or horseradish peroxidase-linked anti-rabbit IgG (1:5000) was used as a secondary antibody (at room temperature for $2 \mathrm{~h}$ ), and antigen-antibody complexes were detected utilizing an enhanced chemiluminescence kit (ECL Plus, Amersham, Freiburg, 
Germany). Densitometry values for western blot and antibody array experiments were estimated with ImageQuant TL software (GE Healthcare, Buckinghamshire, UK) and expressed as arbitrary units (a.u.). Multiple film exposures were used to verify the linearity of the samples analyzed.

\section{Quantitative real-time PCR}

Target gene mRNA expression was detected by quantitative real-time PCR. A375 cells were placed in sixwell plates and treated with the designated reagents. After incubation, cells were collected, and total RNA was isolated utilizing TRIzol® Reagent (Invitrogen, USA). Reverse transcription was performed with the "5×all in one" RT reagent (Abm; Canada). Quantitative PCR was conducted using EvaGreen ${ }^{\circledR}$ Master Mixes (Abm; Canada) according to the manufacturer's instructions. The $\beta$-actin gene was selected as an endogenous control. The primers for MGMT were as follows: forward primer, 5 '-GTT TTC CAG CAA GAG TCG TTC-3'; reverse primer, 5'-GCT GCT AAT TGC TGG TAA GAA A-3'. The primers for $\beta$-actin were as follows: forward primer, 5'-CCT GGC ACC CAG CAC AAT-3'; reverse primer, 5'-GGG CCG GAC TCG TCA TAC -3 .

\section{Immunofluorescence}

The presterilized coverslips were placed in six-well plates, and A375 cells were seeded on the coverslips. After treatment with the designated drugs, cell fixation was carried out utilizing $4 \%$ paraformaldehyde for 30 minutes. The cells were permeabilized using a $0.1 \%$ Triton X-100 solution for fifteen minutes and blocked utilizing $5 \%$ BSA for $1 \mathrm{~h}$. The cells were immunostained overnight using the primary antibody $\mathrm{Y}^{-}$ $\mathrm{H} 2 \mathrm{AX}$ (CST; $1: 100)$ at $4^{\circ} \mathrm{C}$. Then, the cells were incubated with the secondary antibody CoraLite 594conjugated goat anti-rabbit IgG (Proteintech; 1:400) diluted in TBS mixed with DAPI $(1: 10,000)$ for $1 \mathrm{~h}$ at room temperature in the dark. Cells were visualized by fluorescence microscopy (IX5 Obaerver Inverted Microscope; Olympus, Tokyo, Japan).

\section{Statistical analysis}

Data are presented as the mean \pm standard error from at least three independent experiments and were analyzed with Student's t-test. $p<0.05$ was considered statistically significant. All statistical tests and corresponding $\mathrm{P}$ values were two-sided.

\section{Results}

\section{VMF enhances the sensitivity of MM cells to $T M Z$ in vitro and in vivo}

To confirm the appropriate concentration of TMZ for subsequent experiments, the inhibition rates of A375 and Sk-MEL28 cells treated with various concentrations of TMZ were determined in the MTT assay (Fig. S1). As shown in Fig. S1, with an increasing TMZ concentration and application time, the inhibition rates of A375 and SK-MEL28 cells gradually increased. In other words, TMZ inhibited cell growth in a time- and dose-dependent manner. The $\mathrm{IC}_{50}$ values of the A375 and Sk-MEL28 cells were significantly different (see Figure S1), so the TMZ concentration selected in the subsequent MTT assay was different. To confirm 
whether vMF could enhance the chemosensitivity of MM cells to TMZ, cell inhibition was evaluated with the MTT assay. Briefly, A375 and SK-MEL28 cells were treated with different concentrations of VMF (0.02 and $0.04 \mu \mathrm{M})$ and/or $\operatorname{TMZ}(0.3,0.6,0.9,1.2,1.5,1.8$, and $2.1 \mathrm{mM}$ or $0.5,1.0,1.5,2.0,2.5$, and $3.0 \mathrm{mM})$ for $24 \mathrm{~h}$ or $48 \mathrm{~h}$ (Fig. 1A-B). Compared to TMZ alone, combined treatment with vMF increased the inhibition rate of cells. The $I C_{50}$ value of the TMZ+VMF group was lower than that of the TMZ group (Tables 1,2$)$. The results of the MTT assay suggested that the proliferation activity of A375 and Sk-MEL28 cells was decreased significantly by TMZ and that VMF could enhance sensitization to TMZ-induced cytotoxicity. A375 cells were treated with vMF $(0.5$ or $1 \mu \mathrm{M})$ and TMZ $(2 \mathrm{mM})$ for $24 \mathrm{~h}$ either alone or in combination, and the number of apoptotic cells was detected by PI/Annexin V-FITC staining (Fig. 1C-D). The results showed that the apoptosis rate increased from $3.37 \pm 3.00 \%$ in the control group to $28.83 \pm 4.02 \%$ in the TMZ $2 \mathrm{mM}$ group. Compared with TMZ $2 \mathrm{mM}$ treatment alone, treatment with $2 \mathrm{mM} \mathrm{TMZ}$ in combination with $0.5 \mu \mathrm{M}$ or $1 \mu \mathrm{M} v \mathrm{VMF}$ increased the apoptosis rates to $41.37 \pm 3.96 \%$ and $55.53 \pm 5.09 \%$, respectively. The $1 \mu \mathrm{M}$ vMF group and the control group showed no significant difference in the apoptosis rate $(\mathrm{p} \rrbracket$ 0.05). The apoptosis results indicated that VMF can increase TMZ-induced apoptosis in a dose-dependent manner. After treatment, the tumor length and width in nude mice were surveyed every two days, and the tumor volume was calculated. The growth curve of A375 cells in nude mice was drawn with time (day) as the abscissa and tumor volume (cm3) as the ordinate (Fig. 1E). Compared with that in the control group,

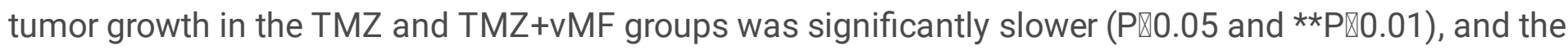
tumor growth in the TMZ+vMF group was slower than that in the TMZ group (Pख0.05). After 21 days of treatment, all groups of nude mice were dissected to remove the xenograft tumors, which were then weighed (Fig. 1E). The tumor weight in the TMZ group and TMZ+VMF group was significantly lower than that in the control group (P凶0.05 and **P®0.01), and the tumor weight in the TMZ+vMF group was also lower than that in the TMZ group (Pख0.05). The above experimental results indicated that VMF can increase the sensitivity of $M M$ to $T M Z$ in vivo and in vitro.

\section{vMF enhances TMZ-induced DNA damage in melanoma}

The protein expression of p-ATR, $\mathrm{y}-\mathrm{H} 2 \mathrm{AX}, \mathrm{p}$-ATM, p-chk1 and p-chk2 was detected after A375 cells were treated with vMF ( 1 and $2 \mu \mathrm{M})$ and/or TMZ $(1 \mathrm{mM})$ by western blot analysis (Fig. 2A). Western blotting showed that $\mathrm{p}-\mathrm{ATR}, \mathrm{y}-\mathrm{H} 2 \mathrm{AX}, \mathrm{p}-\mathrm{ATM}$, $\mathrm{p}$-chk1 and p-chk2 protein expression in the TMZ group, TMZ+vMF 1

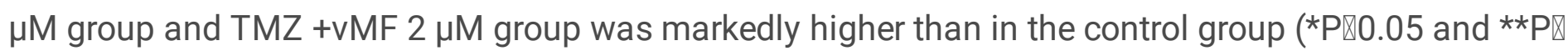
0.01). Furthermore, protein expression in the TMZ group, TMZ +vMF $1 \mu \mathrm{M}$ group and TMZ +vMF $2 \mu \mathrm{M}$ group increased sequentially. The western blotting results demonstrated that VMF can enhance TMZinduced DNA damage in a dose-dependent manner. Immunofluorescence staining was used to detect the effect of vMF on the level of the TMZ-induced DNA damage protein $\mathrm{Y}-\mathrm{H} 2 \mathrm{AX}$ (Fig. 2B).

Immunofluorescence staining results suggested that $\mathrm{Y}-\mathrm{H} 2 \mathrm{AX}$ levels in the control group, TMZ $1 \mathrm{mM}$ group and TMZ $1 \mathrm{mM}+\mathrm{vMF} 1 \mu \mathrm{M}$ group increased sequentially. There was no obvious difference between the 1 $\mu M$ vMF group and the control group. These results indicated that VMF can increase the DNA damage caused by TMZ.

\section{Blocking the ERK pathway downregulates MGMT expression in melanoma}


Similar to U0126, vMF can inhibit the MAPK/ERK signaling pathway and reduce MGMT mRNA and protein levels. The protein phosphorylation of ERK1/2 (p-ERK1/2) and MEK1 (p-MEK1) was detected after A375 cells were treated with $\operatorname{vMF}(0.1,0.5,1.0$, and $2.0 \mu \mathrm{M})$ for $24 \mathrm{~h}$ via western blot analysis (Fig. 3C). The western blotting results showed that the expression of $\mathrm{p}-\mathrm{ERK} 1 / 2$ and $\mathrm{p}-\mathrm{MEK} 1$ in the control group, vMF $0.1 \mu \mathrm{M}$ group, vMF $0.5 \mu \mathrm{M}$ group, vMF $1.0 \mu \mathrm{M}$ group and vMF $2.0 \mu \mathrm{M}$ group decreased sequentially. The results verified that VMF can inhibit the MAPK/ERK signaling pathway. The protein expression of MGMT was detected after A375 cells were treated with vMF (0, 1, 2 and $5 \mu \mathrm{M})$ and/or TMZ (1 mM) for 24 h by western blot analysis (Fig. 3A). Fig. 3A shows that vMF can inhibit the expression level of MGMT and that the inhibitory effect increases as the concentration increases. The expression of MGMT mRNA was determined after A375 cells were treated with $\operatorname{U0126}(0,0.5$ and $1 \mu \mathrm{M})$ (Fig. 3D) or vMF (0, 0.5 and $1 \mu \mathrm{M})$ (Fig. 3B) for $2 \mathrm{~h}, 24 \mathrm{~h}, 48 \mathrm{~h}$ and $72 \mathrm{~h}$ by RT-qPCR. From the RT-qPCR results, it can be seen that the expression of MGMT mRNA shows a significant decline with an increase in the U0126 or vMF concentration and the extension of time. The melanomas of the nude mice were stripped, and total protein was extracted. The expression of MGMT, p-ERK1/2, ERK1/2, p-MEK1 and MEK1 was detected in the control, TMZ and TMZ+vMF groups by western blotting (Fig. 3E). The expression of MGMT, p-ERK1/2 and $\mathrm{p}-\mathrm{MEK} 1$ in the control, $\mathrm{TMZ}$ and TMZ+vMF groups decreased in turn. From the experimental results, it can be concluded that vMF can accelerate the depletion of MGMT by TMZ in vivo and that vMF can inhibit the phosphorylation levels of ERK1/2 and MEK1; these results are consistent with those of in vitro experiments.

\section{Overexpression of MGMT attenuates VMF-induced TMZ sensitization}

To explore whether vMF enhances the cytotoxicity of TMZ to MM by reducing MGMT, we conducted the following experiment. First, MGMT expression was upregulated in A375 cells by transfection with the pcDNA3.1-MGMT plasmid (Fig. 4A). After transfection for $24 \mathrm{~h}$, A375 MGMT OE cells were treated with $0.2 \mu \mathrm{M} v \mathrm{VMF}$ and/or $1 \mathrm{mM}$ TMZ for $36 \mathrm{~h}$, and the expression of MGMT was detected by western blot analysis (Fig. 4B). Western blotting showed that MGMT expression in the MGMT OE-TMZ+vMF group was increased to a greater extent than that in the control-TMZ+vMF group and vector-TMZ+vMF group. Furthermore, the results of MTT assays showed that the $\mathrm{IC}_{50}$ value of the MGMT OE-TMZ+vMF group was markedly increased compared with that of the control-TMZ+vMF and vector-TMZ+vMF groups (Fig. 4C). Our results revealed that MGMT overexpression attenuates vMF-induced TMZ sensitization.

\section{TMZ exposure activates ERK activity in melanoma cells}

The protein expression of p-ERK was detected after A375 cells were treated with TMZ $(0.5,1.0$, and 2.0 $\mathrm{mM}$ ) by western blot analysis (Fig. 5). The outcomes showed that the expression of p-ERK1/2 in the control group, TMZ 0.5 mM group, TMZ 1.0 mM group, and TMZ 2 mM group decreased sequentially. The results verified that TMZ exposure can activate ERK activity in melanoma cells.

\section{MGMT expression was positively correlated with p-ERK1/2 in melanoma tissues}


The expression and intracellular localization of MGMT and p-ERK in the tissue assay were examined by immunohistochemistry. As illustrated in Fig. 6A, 20 cases were MGMT positive, 28 cases were MGMT negative, 30 cases were p-ERK $1 / 2$ positive and 18 cases were $p$-ERK $1 / 2$ negative in the 48 melanoma tissue specimens. Moreover, 19 cases were $\mathrm{p}$-ERK1/2 positive among the 20 MGMT-positive cases, and 17 cases were p-ERK1/2 negative among the 28 MGMT-negative cases (Fig. 6B). The results suggested that the expression of MGMT and p-ERK1/2 in melanoma tissues was positively correlated.

\section{Discussion}

$\mathrm{MM}$ accounts for $1 \%$ to $3 \%$ of all malignant tumors, but in recent decades, $\mathrm{MM}$ has been increasing at a rate of $6 \%$ to $7 \%$ year by year, and the age of onset is showing a younger trend. MM is one of the fastestgrowing types of malignant tumors, and the mortality rate is also increasing each year. Patients with advanced MM progress rapidly and present a poor prognosis, and systemic therapy (chemotherapy, targeted therapy, immunotherapy) is the only option for prolonging their survival. Alkylating agents (such as DTIC and TMZ) and v (CDDP) are classic chemotherapy drugs for advanced MM. The alkylation of the $\mathrm{O}^{6}$ position on guanine causes the insertion of thymine instead of cytosine during DNA replication, thereby inducing the cell cycle to arrest in G2/M and ultimately causing apoptosis. TMZ is a common alkylating agent for the treatment of advanced melanoma. A large European phase III clinical study compared TMZ and DTIC as first-line treatments for patients with advanced MM. This study indicated that TMZ was more efficient and that PFS under this treatment surpassed that under treatment with DTIC, but OS was not significantly improved[8] . The therapeutic effect of TMZ was determined by its capability to alkylate and/or methylate DNA in exposed cells. However, tumor cells can repair this type of DNA damage, which reduces the therapeutic effect and leads to the development of drug resistance. This phenomenon makes investments targeting TMZ resistance mechanisms and reversing resistance necessary.

The primary mechanism underlying TMZ resistance is the DNA repair system. DNA damage repair (DDR) is involved in the repair of the DNA damage caused by TMZ and chloroethyl-nitrosoureas (CNUs) $[9,14$, 15] . $0^{6}$-methylguanine-DNA methyltransferase (MGMT) is the most crucial mechanism for repairing DNA damage caused by TMZ. MGMT can directly remove $0^{6}$-meG through replacement, and the MGMT enzyme is irreversibly inactivated in this process. Since MGMT possesses an efficient repair function for DNA damage caused by alkylating agents, the expression of MGMT can be employed as an index to predict the effect of TMZ in glioblastoma (GBM) $[16,17]$. The $30-60 \%$ of GBM patients with MGMT gene silencing induced by hypermethylation in the promoter region are more likely to benefit from alkylating agent-based chemotherapy to achieve longer survival times $[18,19]$. As an important DDR protein, MGMT is widely expressed in normal human tissues but is generally highly expressed in all types of human tumors, including melanoma, lung cancer, glioma, leukemia, lymphoma and colon cancer, etc. [20] . Among DNA repair systems, MGMT-mediated repair is unique. First, MGMT works alone and does not depend on any other proteins or co-factors. It transfers alkyl groups to internal cysteine residues, acting as both a transferase and a receptor for alkyl groups. Next, MGMT irreversibly inactivates itself when it 
receives alkyl groups from guanine, so it is a suicidal protein. Finally, MGMT restores DNA damage stoichiometrically. Therefore, adjusting the activity of MGMT might increase the efficacy of chemotherapy using alkylating agents[21]. Since MGMT is a key factor determining the resistance of alkylating agents, the inhibition of MGMT is expected to reverse the resistance of alkylating agents and improve the therapeutic effect of MM.

Many studies have evaluated agents such as streptozotocin (STZ) and dacarbazine. that can suppress the activity of MGMT. Similar to TMZ, these agents can also cause DNA alkylation and reduce the activity of intracellular MGMT by consuming MGMT, thereby increasing the sensitivity of tumor cells to chloroethyl drugs[22, 23]. However, when cancer patients receive alkylating agents and nitrosourea treatment sequentially, serious blood toxicity can occur[24,25]. These studies indicated that reducing the activity of MGMT by alkylating agents is not an appropriate strategy for improving the chemotherapeutic effect of chloroethyl drugs. Another way to inhibit MGMT is to develop specific inhibitors of this protein. To identify effective MGMT inhibitors, Moschel et al. prepared many guanine derivatives. According to their data, the ranking of the inhibition effect of MGMT is as follows: $0^{6}-(4-Y$-benzyl) guanine $(Y=H, F, C l$ and $\mathrm{CH} 3)>\mathrm{O}^{6}$-benzyl-2j-deoxyguanosine $\left(\mathrm{O}^{6}-\mathrm{BdG}, 3\right)>\mathrm{O}^{6}$-(4-Y-benzyl) guanosine $(\mathrm{Y}=\mathrm{H}, \mathrm{Cl}$ and $\mathrm{CH} 3)>9$ substituted $\mathrm{O}^{6}$-BG derivatives $>0^{6}$-allylguanine $>0^{6}$-benzyl hypoxanthine $>0^{6}-\mathrm{MG}[26-28]$. These experimental outcomes present a theoretical basis for the combination of alkylating agents and endocrine therapy. Since MGMT is irreversibly inactivated after it participates in DNA repair, the activity of MGMT in the cell is mainly positively correlated with the protein level of MGMT in the cell.

It is assumed that an ideal MGMT inhibitor should possess certain features, such as a high efficiency and low side effects, and it should be ideal if such an inhibitor could be found among mature drugs that are already being applied in clinical proceedings. Although several MGMT inhibitors have been synthesized and evaluated, no MGMT-specific inhibitor has been approved for clinical application thus far. An agent with a target other than MGMT that indirectly suppresses MGMT expression may contribute to research on MGMT inhibition. Our data showed that the ERK inhibitor VMF can downregulate the expression of MGMT in the A375 and Sk-MEL28 melanoma cell lines, which demonstrated that the ERK inhibitor vMF may increase TMZ cytotoxicity in melanoma cells. In a previous report, Sato A et al. showed that MEK inhibitors could reverse the drug resistance of glioblastoma cells to temozolomide and that MEK inhibitors combined with TMZ effectively control the occurrence and development of glioblastoma cells. Targeting the MEK-ERK-MDM2-p53 pathway combined with TMZ may be a novel and promising treatment for glioblastoma[13] . Although there have been related studies on the molecular mechanism of MGMT regulation in glioblastoma, the signal transduction pathway regulating MGMT in melanoma cells has not been elucidated. To our knowledge, this is the first investigation of the use of VMF for TMZ sensitization as an ERK inhibitor in melanoma. To further confirm whether vMF functions via the ERKMGMT pathway, we performed an analysis that revealed that high expression of MGMT could reverse the sensitization effect of ERK inhibitors on TMZ. In the past, MGMT inhibitors have shown high blood toxicity and poor effects, which has limited their clinical application. Since the ERK inhibitor vMF was approved by the FDA in 2011 and has since been widely applied in the clinical management of MM, this 
oral targeted drug is rarely discontinued due to adverse reactions, which helps to elucidate the mechanism of MGMT inhibitors used as TMZ sensitization agents. Moreover, vMF can cross the bloodbrain barrier, so it might be used to treat patients with unresectable or metastatic melanoma with the $\mathrm{BRAF}^{\mathrm{V} 600 \mathrm{E}}$ mutation.

Studies have shown that MEK/ERK signals are constitutively activated due to the upregulation or abnormalities of upstream molecules of tyrosine kinase receptors (EGFR, PDGFR, etc.) $[29,30]$. Previous research investigating the connection of MEK/ERK signaling and MGMT expression levels illustrated that the MEK inhibitors U0126 and SL327 inhibited the expression of MGMT in GSCs by activating p53. MGMT inhibitors can inhibit the expression of MGMT and regulate GSC resistance to TMZ[31] . This evidence suggested that MEK activity could be necessary to maintain MGMT expression in GSCs and that MEK inhibitors may exert a sensitization effect on TMZ chemotherapy in GSCs. These findings suggested that therapies targeting MEK/ERK signaling might be a potential option for the treatment of TMZ-resistant cases. PLX4720 can inhibit the kinase activity of the most common BRAF mutation in vitro, in which the valine at codon 600 of exon 15 is replaced by glutamate (V600E) [32] . VMF is a compound whose structure is closely related to that of its precursor PLX4720[33] . It is a derivative of PLX4720, which reversibly and highly selectively binds the ATP-binding domain of the mutant BRAF monomer[34] and reduces ERK1/2 phosphorylation and cyclin D1 levels, which may lead to the suppression of cell proliferation[35] . The BRAF, ARAF and CRAF (also known as RAF1) proteins belong to the RAF family and are involved in cell growth. Mutations could occur at different sites in the BRAF gene, and V600E (valine in codon 600 replaced by glutamic acid) accounts for $80 \%$ of mutation events[36] ; another V600K mutation occurs in $16 \%$ of total mutation cases, while approximately $3 \%$ harbor the V600D/R mutation. All of these mutations cause abnormal constitutive activation of the BRAF protein. BRAF inhibitors could result in significant survival benefits for melanoma patients with BRAF ${ }^{\mathrm{V} 600}$ mutations. However, drug resistance to BRAF inhibitors is still the main problem faced by patients with MM, which is also the cause of disease recurrence within a few months after treatment. Patients with BRAF-resistant melanoma generally harbor other mutations that can reactivate the MAPK pathway, such as MEK1 mutations and BRAF or KRAS amplification [37]. The frequent coactivation of MEK in BRAF-resistant tumors led to the development of a combined therapy involving BRAF inhibitors and MEK inhibitors (such as trametinib) that can effectively improve the survival rate but cannot prevent disease recurrence[38] . The relationship between MAPK/ERK pathway activity and MGMT expression levels in malignant black tissue has yet to be recorded in the literature. We employed a tissue microarray method to determine that the expression levels of MGMT and p-ERK $1 / 2$ were positively correlated in melanoma tissues. In addition, our in vitro experiments demonstrated that ERK pathway activity in cells will further increase after TMZ exposure. This may be the protective response of cells to toxic drugs, which may further mediate drug resistance. Our data indicated clinical prospects for the VMF sensitization strategy. First, ERK phosphorylation was positively associated with MGMT expression in melanoma tissue samples. Studies have demonstrated that there are many reasons for the abnormal activation of ERK, among which BRAF mutation might be an important initiator. Our results illustrated that VMF can inhibit MGMT while suppressing ERK activity. This provides a theoretical basis for the combined use of VMF and TMZ to treat MM patients with BRAF mutations. In the 
next step of this work, after tumor cells were treated with TMZ, the ERK pathway was activated, and the expression of MGMT increased. This was one of the causes of tumor cell resistance to TMZ. Since TMZ can consume MGMT, the results did not show that the expression of MGMT was increased. Therefore, whether the combination of VMF and TMZ may enhance the efficacy and prolong the survival time of patients with a BRAF mutation or wild-type MM is a question worth studying. In summary, our research suggests that the combination of chemotherapy and ERK inhibitors can be expected to inhibit the subdrug resistance mechanism.

\section{Conclusion}

Our experimental results indicate that the ERK pathway inhibitor VMF can increase the sensitivity of melanoma cell lines to TMZ in vivo and in vitro by downregulating MGMT levels. MGMT and p-ERK1/2 protein expression levels are positively correlated. The combination of VMF and TMZ is expected to be a useful strategy in the clinical treatment of MM.

\section{Abbreviations}

TMZ Temozolomide

MGMT 06-methylguanine-DNA methyltransferase

vMF Vemurafenib

MM Malignant melanoma

FDA The Food and Drug Administration

PFS Progression-free survival

OS Overall survival

ORR Overall response rates

DTIC Dacarbazine

GBM Glioblastoma

CDDP Cisplatin

DDR DNA damage repair

CNUs Chloroethyl-nitrosoureas

STZ Streptozotocin 


\section{Declarations}

\section{Ethics approval and consent to participate}

Animals were maintained in the Laboratory Animal Center of the First Affiliated Hospital of Soochow University, in accordance with the Soochow University Institutional Animal Care and Use Committee. All human tissues in tissue arrays were collected under IRB- and HIPPA-approved protocols. All samples tested negative for HIV and hepatitis B or their counterparts in animals and were approved for commercial product development.

\section{Availability of data and materials}

The datasets during and/or analysed during the current study available from the corresponding author on reasonable request.

\section{Funding}

This work was supported by the National Natural Science Foundation of China $(81402477,81602802)$, Natural Science Foundation of Jiangsu Province of China (BK20140295) and Jiangsu Government Scholarship for Oversea Studies ([2018] No. 73).

\section{Consent for publication}

All authors have agreed to the publication of the article.

\section{Competing interests}

There is no financial or personal relationship with other people or organizations that could inappropriately influence (bias) this work.

\section{Affiliations}

Department of Oncology, The First Affiliated Hospital of Soochow University, suzhou, 215031, Jiangsu, China

Bingjie Ren, Qiang Li, Yingxi Hu, Mengyao Wu, Dapeng Li, Daoming Li, Min Tao, Rongrui Liang

Departemnt of Radiation Oncology, The First Affiliated Hospital of Soochow University, suzhou, 215031, Jiangsu, China

Jing Zhao

Department of Chemotherapy, Jiangxi Cancer Hospital, Nanchang, 330029, Jiangxi, China

Qiang Li 
Bingjie Ren: Investigation, Writing - Original Draft. Qiang Li: Investigation, Data Curation. Jing Zhao: Resources, Methodology, Data Curation. Xia Guo: Investigation. Yingxi Hu: Resources. Mengyao Wu: Formal Analysis. Dapeng Li: Resources. Daoming Li: Formal Analysis. Min Tao: Conceptualization, Methodology, Supervision. Rongrui Liang: Conceptualization, Methodology, Supervision, WritingReviewing and Editing.

Corresponding author

Correspondence to Min Tao and Rongrui Liang.

Acknowledgements

Not applicable.

\section{References}

1. Siegel RL, Miller KD, Jemal A: Cancer statistics, 2020. CA Cancer J Clin 2020, 70(1):7-30.

2. Kanaki T, Stang A, Gutzmer R, Zimmer L, Chorti E, Sucker A, Ugurel S, Hadaschik E, Gräger NS, Satzger I et al: Impact of American Joint Committee on Cancer 8th edition classification on staging and survival of patients with melanoma. Eur J Cancer 2019, 119:18-29.

3. Chapman PB, Hauschild A, Robert C, Haanen JB, Ascierto P, Larkin J, Dummer R, Garbe C, Testori A, Maio $M$ et al: Improved survival with vemurafenib in melanoma with BRAF V600E mutation. $N$ Engl $J$ Med 2011, 364(26):2507-2516.

4. McArthur GA, Chapman PB, Robert C, Larkin J, Haanen JB, Dummer R, Ribas A, Hogg D, Hamid O, Ascierto PA et al: Safety and efficacy of vemurafenib in BRAF(V600E) and BRAF(V600K) mutationpositive melanoma (BRIM-3): extended follow-up of a phase 3, randomised, open-label study. Lancet Oncol 2014, 15(3):323-332.

5. Chapman PB, Robert C, Larkin J, Haanen JB, Ribas A, Hogg D, Hamid O, Ascierto PA, Testori A, Lorigan PC et al: Vemurafenib in patients with BRAFV600 mutation-positive metastatic melanoma: final overall survival results of the randomized BRIM-3 study. Ann Oncol 2017, 28(10):2581-2587.

6. Malmström A, Grønberg BH, Marosi C, Stupp R, Frappaz D, Schultz H, Abacioglu U, Tavelin B, Lhermitte B, Hegi ME et al: Temozolomide versus standard 6-week radiotherapy versus hypofractionated radiotherapy in patients older than 60 years with glioblastoma: the Nordic randomised, phase 3 trial. Lancet Oncol 2012, 13(9):916-926.

7. Stupp R, Mason WP, van den Bent MJ, Weller M, Fisher B, Taphoorn MJ, Belanger K, Brandes AA, Marosi C, Bogdahn $U$ et al: Radiotherapy plus concomitant and adjuvant temozolomide for glioblastoma. N Engl J Med 2005, 352(10):987-996.

8. Middleton MR, Grob JJ, Aaronson N, Fierlbeck G, Tilgen W, Seiter S, Gore M, Aamdal S, Cebon J, Coates A et al: Randomized phase III study of temozolomide versus dacarbazine in the treatment of 
patients with advanced metastatic malignant melanoma. J Clin Oncol 2000, 18(1):158-166.

9. Baran K, Yang M, Dillon CP, Samson LL, Green DR: The proline rich domain of p53 is dispensable for MGMT-dependent DNA repair and cell survival following alkylation damage. Cell Death Differ 2017, 24(11):1925-1936.

10. Forte IM, Indovina P, Iannuzzi CA, Cirillo D, Di Marzo D, Barone D, Capone F, Pentimalli F, Giordano A: Targeted therapy based on p53 reactivation reduces both glioblastoma cell growth and resistance to temozolomide. Int J Oncol 2019, 54(6):2189-2199.

11. Ogura R, Tsukamoto Y, Natsumeda M, Isogawa M, Aoki H, Kobayashi T, Yoshida S, Okamoto K, Takahashi H, Fujii Y et al: Immunohistochemical profiles of IDH1, MGMT and P53: practical significance for prognostication of patients with diffuse gliomas. Neuropathology 2015, 35(4):324335.

12. Chen X, Zhang M, Gan H, Wang H, Lee JH, Fang D, Kitange GJ, He L, Hu Z, Parney IF et al: A novel enhancer regulates MGMT expression and promotes temozolomide resistance in glioblastoma. Nature communications 2018, 9(1):2949.

13. Sato A, Sunayama J, Matsuda K, Seino S, Suzuki K, Watanabe E, Tachibana K, Tomiyama A, Kayama T, Kitanaka C: MEK-ERK signaling dictates DNA-repair gene MGMT expression and temozolomide resistance of stem-like glioblastoma cells via the MDM2-p53 axis. Stem Cells 2011, 29(12):19421951.

14. Roos WP, Nikolova T, Quiros S, Naumann SC, Kiedron O, Zdzienicka MZ, Kaina B: Brca2/Xrcc2 dependent HR, but not NHEJ, is required for protection against $\mathrm{O}(6)$-methylguanine triggered apoptosis, DSBs and chromosomal aberrations by a process leading to SCEs. DNA Repair (Amst) 2009, 8(1):72-86.

15. Quiros S, Roos WP, Kaina B: Processing of 06-methylguanine into DNA double-strand breaks requires two rounds of replication whereas apoptosis is also induced in subsequent cell cycles. Cell Cycle 2010, 9(1):168-178.

16. Dahlrot RH, Dowsett J, Fosmark S, Malmstrom A, Henriksson R, Boldt H, de Stricker K, Sorensen MD, Poulsen HS, Lysiak M et al: Prognostic value of 0-6-methylguanine-DNA methyltransferase (MGMT) protein expression in glioblastoma excluding nontumour cells from the analysis. Neuropathol App/ Neurobiol 2018, 44(2):172-184.

17. Stupp R, Hegi ME, Gilbert MR, Chakravarti A: Chemoradiotherapy in malignant glioma: standard of care and future directions. J Clin Oncol 2007, 25(26):4127-4136.

18. Hegi ME, Diserens AC, Gorlia T, Hamou MF, de Tribolet N, Weller M, Kros JM, Hainfellner JA, Mason W, Mariani $L$ et al: MGMT gene silencing and benefit from temozolomide in glioblastoma. $N$ Engl J Med 2005, 352(10):997-1003.

19. Happold C, Stojcheva N, Silginer M, Weiss T, Roth P, Reifenberger G, Weller M: Transcriptional control of $\mathrm{O}(6)$-methylguanine DNA methyltransferase expression and temozolomide resistance in glioblastoma. J Neurochem 2018, 144(6):780-790. 
20. Jiang G, Jiang AJ, Xin Y, Li LT, Cheng Q, Zheng JN: Progression of O(6)-methylguanine-DNA methyltransferase and temozolomide resistance in cancer research. Mol Biol Rep 2014, 41(10):66596665 .

21. Hegi ME, Liu L, Herman JG, Stupp R, Wick W, Weller M, Mehta MP, Gilbert MR: Correlation of 06methylguanine methyltransferase (MGMT) promoter methylation with clinical outcomes in glioblastoma and clinical strategies to modulate MGMT activity. J Clin Oncol 2008, 26(25):41894199.

22. Kaina B, Margison GP, Christmann M: Targeting O凶-methylguanine-DNA methyltransferase with specific inhibitors as a strategy in cancer therapy. Cell Mol Life Sci 2010, 67(21):3663-3681.

23. Sun $G$, Zhao L, Zhong R, Peng Y: The specific role of O(6)-methylguanine-DNA methyltransferase inhibitors in cancer chemotherapy. Future Med Chem 2018, 10(16):1971-1996.

24. Micetich KC, Futscher B, Koch D, Fisher RI, Erickson LC: Phase I study of streptozocin- and carmustine-sequenced administration in patients with advanced cancer. J Natl Cancer Inst 1992, 84(4):256-260.

25. Panella TJ, Smith DC, Schold SC, Rogers MP, Winer EP, Fine RL, Crawford J, Herndon JE, 2nd, Trump DL: Modulation of 06-alkylguanine-DNA alkyltransferase-mediated carmustine resistance using streptozotocin: a phase I trial. Cancer Res 1992, 52(9):2456-2459.

26. Moschel RC, McDougall MG, Dolan ME, Stine L, Pegg AE: Structural features of substituted purine derivatives compatible with depletion of human 06-alkylguanine-DNA alkyltransferase. J Med Chem 1992, 35(23):4486-4491.

27. Chae MY, McDougall MG, Dolan ME, Swenn K, Pegg AE, Moschel RC: Substituted O6-benzylguanine derivatives and their inactivation of human 06-alkylguanine-DNA alkyltransferase. J Med Chem 1994, 37(3):342-347.

28. Chae MY, Swenn K, Kanugula S, Dolan ME, Pegg AE, Moschel RC: 8-Substituted 06-benzylguanine, substituted 6(4)-(benzyloxy)pyrimidine, and related derivatives as inactivators of human 06alkylguanine-DNA alkyltransferase. J Med Chem 1995, 38(2):359-365.

29. Wee P, Wang Z: Epidermal Growth Factor Receptor Cell Proliferation Signaling Pathways. Cancers (Basel) 2017, 9(5).

30. Mizoguchi M, Betensky RA, Batchelor TT, Bernay DC, Louis DN, Nutt CL: Activation of STAT3, MAPK, and AKT in malignant astrocytic gliomas: correlation with EGFR status, tumor grade, and survival. $J$ Neuropathol Exp Neuro/ 2006, 65(12):1181-1188.

31. Harris LC, Remack JS, Houghton PJ, Brent TP: Wild-type p53 suppresses transcription of the human 06-methylguanine-DNA methyltransferase gene. Cancer Res 1996, 56(9):2029-2032.

32. Tsai J, Lee JT, Wang W, Zhang J, Cho H, Mamo S, Bremer R, Gillette S, Kong J, Haass NK et al: Discovery of a selective inhibitor of oncogenic B-Raf kinase with potent antimelanoma activity. ProC Natl Acad Sci U S A 2008, 105(8):3041-3046.

33. Michaelis M, Rothweiler F, Nerreter T, Van Rikxoort M, Sharifı M, Wiese M, Ghafourian T, Cinatl J: Differential effects of the oncogenic BRAF inhibitor PLX4032 (vemurafenib) and its progenitor 
PLX4720 on ABCB1 function. J Pharm Pharm Sci 2014, 17(1):154-168.

34. Huang T, Karsy M, Zhuge J, Zhong M, Liu D: B-Raf and the inhibitors: from bench to bedside. $J$ Hematol Oncol 2013, 6:30.

35. Jang S, Atkins MB: Which drug, and when, for patients with BRAF-mutant melanoma? Lancet Oncol 2013, 14(2):e60-69.

36. Dankner M, Rose AAN, Rajkumar S, Siegel PM, Watson IR: Classifying BRAF alterations in cancer: new rational therapeutic strategies for actionable mutations. Oncogene 2018, 37(24):3183-3199.

37. Srivenugopal KS, Shou J, Mullapudi SR, Lang FF, Jr., Rao JS, Ali-Osman F: Enforced expression of wild-type p53 curtails the transcription of the $O(6)$-methylguanine-DNA methyltransferase gene in human tumor cells and enhances their sensitivity to alkylating agents. Clin Cancer Res 2001, 7(5):1398-1409.

38. Eich M, Roos WP, Nikolova T, Kaina B: Contribution of ATM and ATR to the resistance of glioblastoma and malignant melanoma cells to the methylating anticancer drug temozolomide. Mol Cancer Ther 2013, 12(11):2529-2540.

\section{Tables}

Table 1. IC $\mathrm{C}_{50}$ values of $\mathrm{A} 375$ cells $(\mathrm{mM})$

\begin{tabular}{|cclcl|}
\hline Time & TMZ & TMZ+vMF 0.02 $\mu \mathrm{M}$ & TMZ & TMZ+vMF 0.04 $\mu \mathrm{M}$ \\
\hline $24 \mathrm{~h}$ & 1.04 & 0.62 & 1.05 & 0.47 \\
\hline $48 \mathrm{~h}$ & 0.62 & 0.26 & 0.49 & 0.31 \\
\hline
\end{tabular}

TMZ, temozolomide. vMF, vemurafenib.

Table 2. IC 50 values of SK-MEL28 cells (mM)

\begin{tabular}{|cclcl|}
\hline Time & TMZ & TMZ+vMF 0.02 $\mu \mathrm{M}$ & $\mathrm{TMZ}$ & $\mathrm{TMZ}+\mathrm{VMF} 0.04 \mu \mathrm{M}$ \\
\hline $24 \mathrm{~h}$ & 3.39 & 2.50 & 3.23 & 2.39 \\
\hline $48 \mathrm{~h}$ & 2.10 & 1.71 & 1.99 & 1.53 \\
\hline
\end{tabular}

TMZ, temozolomide. vMF, vemurafenib.

\section{Figures}



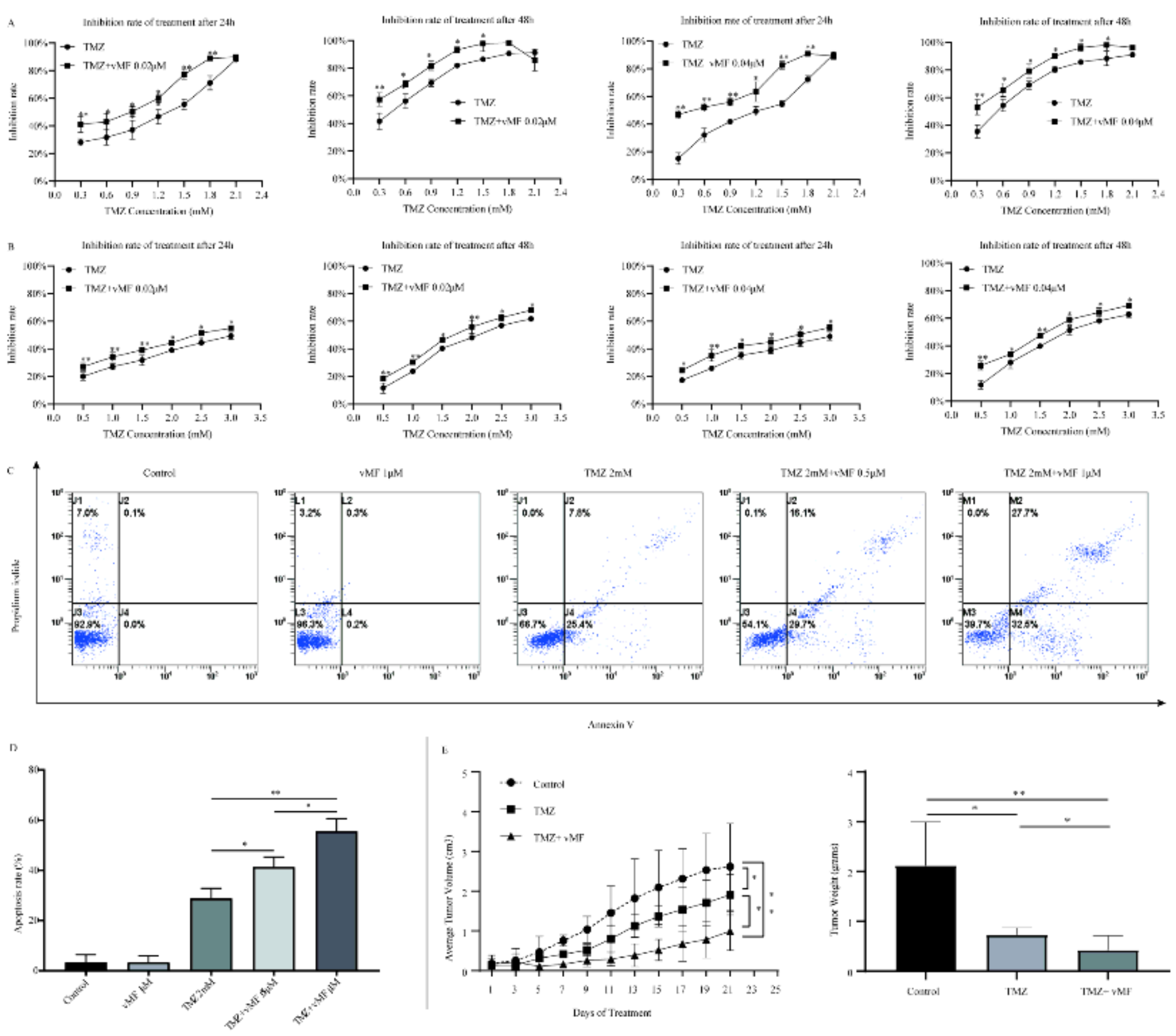

Figure 1

VMF enhanced the sensitivity of MM cells to TMZ in vitro and in vivo A. A375 cells were treated with $T M Z$ and/or vMF $(0.02$ and $0.04 \mu \mathrm{M})$ for $24 \mathrm{~h}$ and $48 \mathrm{~h}$. The cell inhibition rate of $\mathrm{A} 375$ cells ( ${ }^{\star P} \otimes 0.05,{ }^{*} \mathrm{P} \otimes 0.01$ vs. TMZ group). B. Sk-MEL28 cells were treated with TMZ and/or vMF (0.02 and $0.04 \mu M)$ for $24 \mathrm{~h}$ and 48 h. The cell inhibition rate of Sk-MEL28 cells ( ${ }^{*} \otimes \otimes 0.05,{ }^{*} \mathrm{P} \otimes 0.01 \mathrm{vs}$. TMZ group). C-D. The apoptosis rate of A375 cells treated with VMF $(0.5$ and $1.0 \mu \mathrm{M})$ and TMZ $(2 \mathrm{mM})$, alone or in combination, was analyzed by flow cytometry PI/Annexin $\vee$ staining ( ${ }^{\star} \mathrm{P} \bigotimes 0.05,{ }^{\star} * \mathrm{P} \unrhd 0.01 \mathrm{vs}$. the indicated treatment). The experiments were repeated 3 times independently. E. MM growth curve in nude mice (left); average tumor weight of

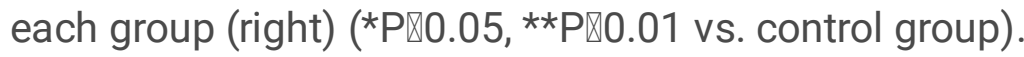



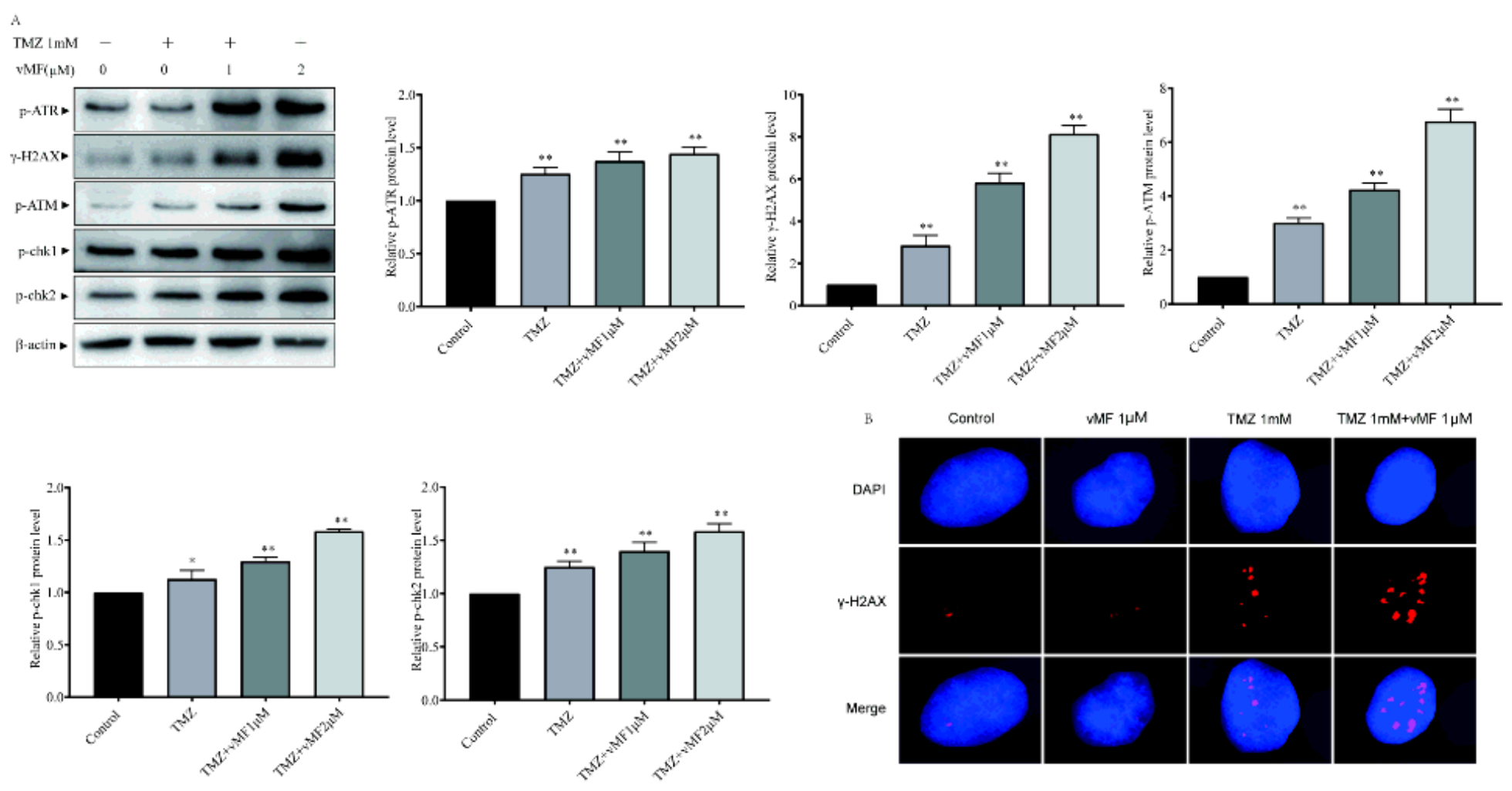

\section{Figure 2}

vMF enhanced TMZ-induced DNA damage in melanoma A. The protein expression of $p-A T R, y-H 2 A X, p-$ ATM, p-chk1 and p-chk2 was detected after A375 cells were treated with TMZ (1 mM) and VMF ( 1 and 2 $\mu \mathrm{M})$ for $24 \mathrm{~h}$ by western blot analysis (*Pख0.05, ${ }^{\star *} \mathrm{P} \otimes 0.01 \mathrm{vs}$. the indicated treatment). B. Measurement of DNA damage in A375 cells treated with TMZ $(1 \mathrm{mM})$ and/or vMF $(1 \mu \mathrm{M})$ for $24 \mathrm{~h}$. Immunofluorescence staining analysis of $\mathrm{Y}-\mathrm{H} 2 \mathrm{AX}$ (red) in A375 cells. DAPI (blue) was used to stain nuclei (representative fields at $\times 200$ magnification). 

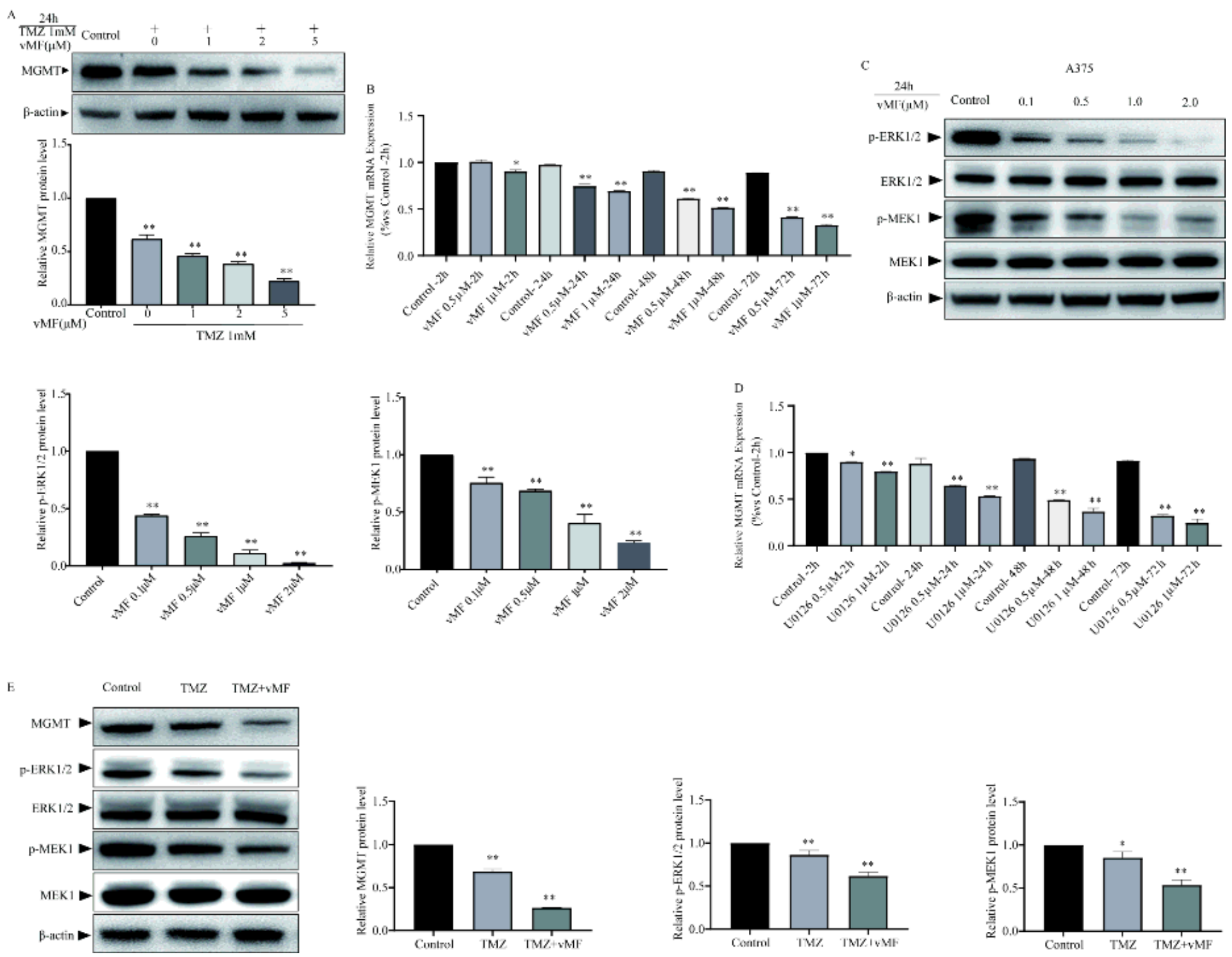

\section{Figure 3}

Blocking the ERK pathway downregulates MGMT expression in melanoma A. The protein expression of MGMT was detected after A375 cells were treated with $\operatorname{TMZ}(1 \mathrm{mM})$ and VMF $(0,1,2$ and $5 \mu \mathrm{M})$ for $24 \mathrm{~h}$ by western blot analysis ( ${ }^{*} \mathrm{P} \otimes 0.05,{ }^{\star} * \mathrm{P} \bigotimes 0.01$ vs. control group). B. RT-qPCR analysis of MGMT mRNA expression in A375 cells treated with vMF $(0.5$ and $1 \mu \mathrm{M})$ for $2 \mathrm{~h}, 24 \mathrm{~h}, 48 \mathrm{~h}$ and $72 \mathrm{~h}\left({ }^{\star} \mathrm{P} \otimes 0.05, \star \star \mathrm{P} \otimes 0.01\right.$ vs. control-2 $\mathrm{h}$ group). C. The protein expression of $\mathrm{p}$-ERK1/2 and p-MEK1 was detected after A375 cells were treated with vMF $(0.1,0.5,1.0$ and $2.0 \mu \mathrm{M})$ for $24 \mathrm{~h}$ by western blot analysis ( ${ }^{\star} \mathrm{P} \otimes 0.05$, ${ }^{\star *} \mathrm{P} \otimes 0.01 \mathrm{vs}$. control group). D. RT-qPCR analysis of MGMT mRNA expression in A375 cells treated with U0126 (0.5 and $1 \mu \mathrm{M}$ ) for $2 \mathrm{~h}, 24 \mathrm{~h}, 48 \mathrm{~h}$ and $72 \mathrm{~h}$ ( ${ }^{\star P} \otimes 0.05,{ }^{\star} \mathrm{P} \otimes 0.01 \mathrm{vs}$. control-2 $\mathrm{h}$ group). E. The expression of MGMT, $\mathrm{p}-$ ERK1/2 and $\mathrm{p}-\mathrm{MEK} 1$ in MM in nude mice was analyzed by western blotting ( ${ }^{*} \mathbb{P} \otimes 0.05,{ }^{*} \mathrm{P} \otimes 0.01 \mathrm{vs}$. control group). 


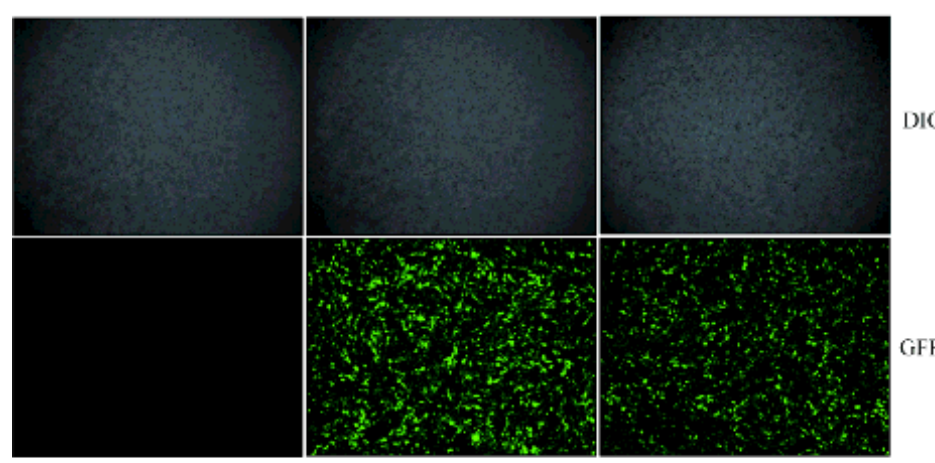

$\begin{array}{ll}\text { B } & \text { A375 }\end{array}$

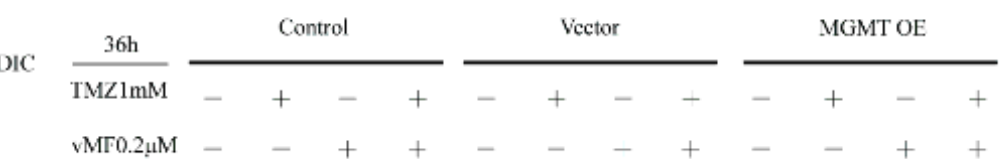

GFP
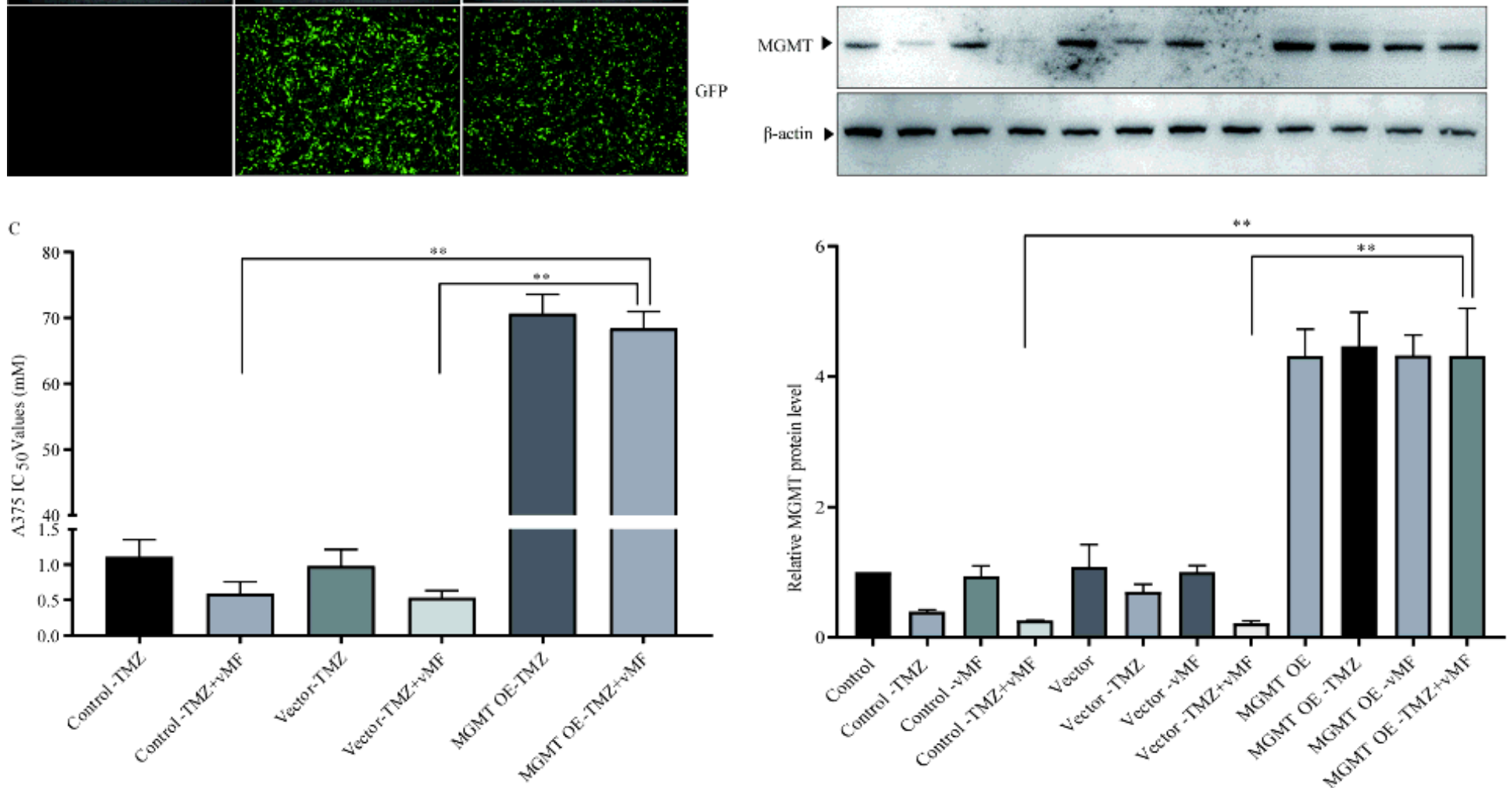

Figure 4

Overexpression of MGMT attenuates vMF-induced TMZ sensitization A. After transfection with the pcDNA3.1-MGMT plasmid or the pcDNA3.1 empty vector for $24 \mathrm{~h}, \mathrm{~A} 375$ cells were observed for the expression of the MGMT-GFP protein by fluorescence microscopy (representative fields at $\times 40$ magnification). B. A375 cells were treated with TMZ $(1 \mathrm{mM})$ and/or VMF $(0.2 \mu \mathrm{M})$ for $36 \mathrm{~h}$ after transfection with the pcDNA3.1-MGMT plasmid or the pcDNA3.1 empty vector. Western blot analysis of MGMT protein levels ( ${ }^{*} \otimes \square 0.05,{ }^{*} \mathrm{P} \otimes 0.01$ vs. the indicated treatment). C. A375 cells were treated with TMZ and $0.04 \mu \mathrm{M} v \mathrm{VF}$ for $24 \mathrm{~h}$ after transfection with the pcDNA3.1-MGMT plasmid or the pcDNA3.1 empty vector for $24 \mathrm{~h}$. The cell inhibition rate was determined with the MTT assay. The IC50 value was calculated with SPSS (*P囚0.05, ${ }^{\star * P} \otimes 0.01$ vs. the indicated treatment). 

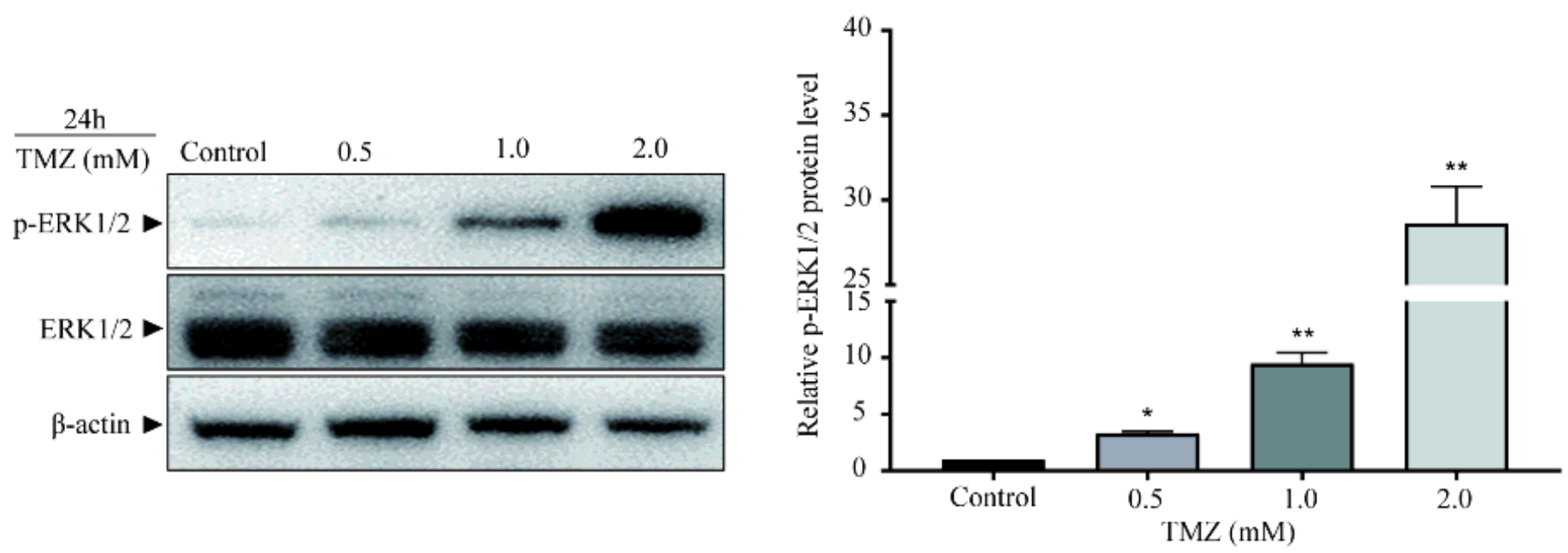

Figure 5

TMZ exposure activates ERK activity in melanoma cells $A$. The protein expression of $p$-ERK $1 / 2$ was detected after $A 375$ cells were treated with $\operatorname{TMZ}(0.5,1.0$, and $2.0 \mathrm{mM})$ for $24 \mathrm{~h}$ by western blot analysis (*P囚0.05, **P $₫ 0.01$ vs. control group).

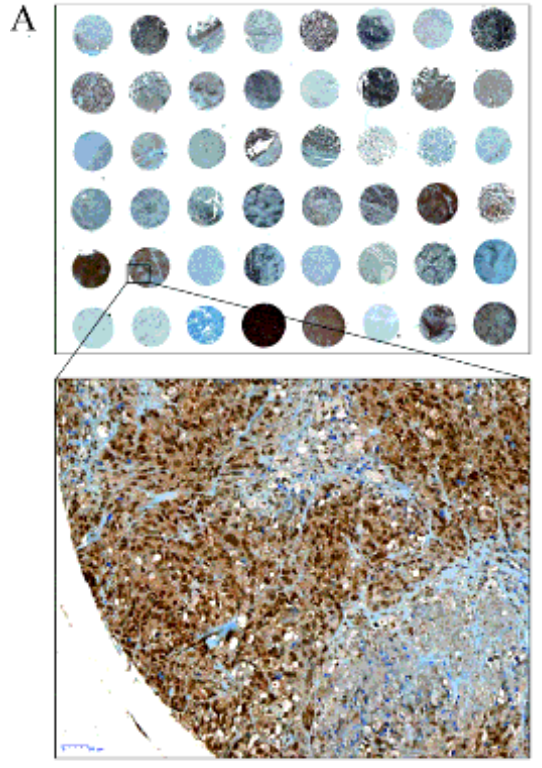

MGMT
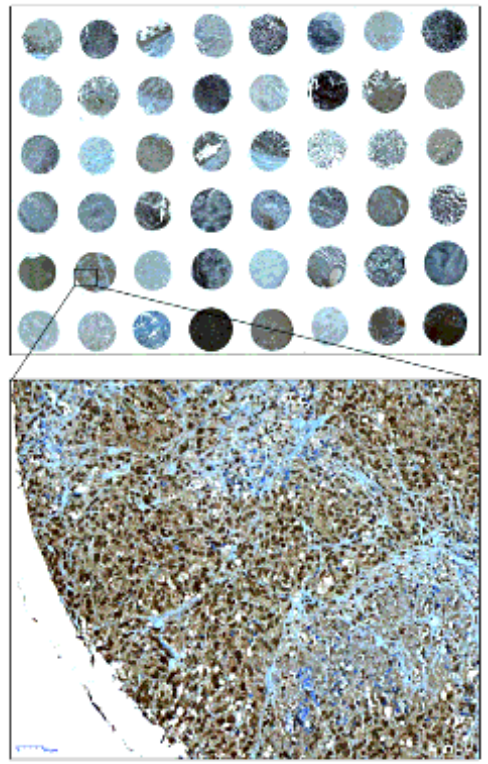

p-ERK $1 / 2$
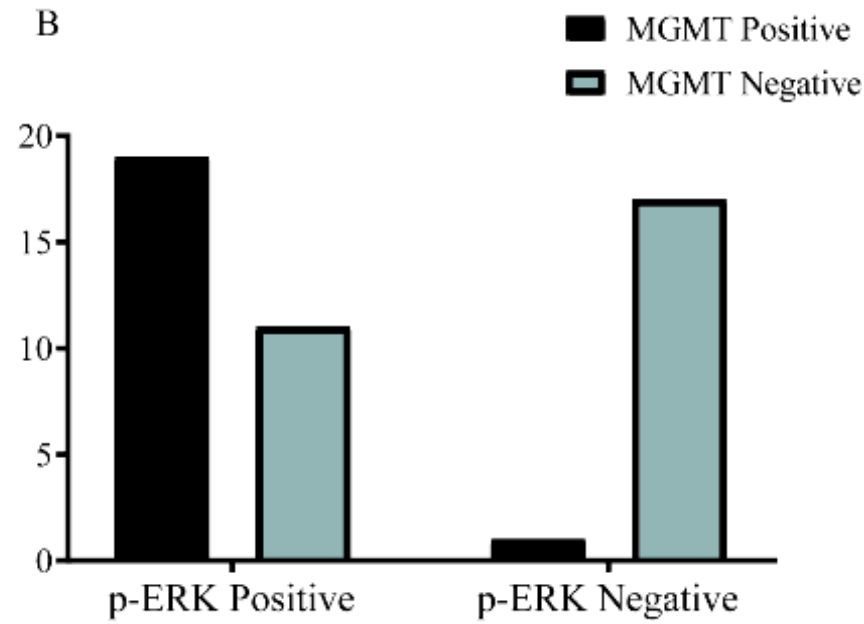

Figure 6

MGMT expression is positively correlated with p-ERK1/2 in melanoma tissues A. MGMT (left) and pERK1/2 (right) immunohistochemistry results in MM tissue chips (48 cases). B. Correlation analysis of MGMT and p-ERK1/2 expression in MM tissue chips (48 cases).

\section{Supplementary Files}

This is a list of supplementary files associated with this preprint. Click to download. 
- FigureS1.png

Page 23/23 